Journal of Social Sciences 7 (4): 575-578, 2011

ISSN 1549-3652

(C) 2011 Science Publications

\title{
Ways of Fishery Local Life: Processes of Participation in Management of Natural Resources in the Coastal Areas of the Upper Gulf of Eastern Area
}

\author{
Sulak Sa-Ngiamlak, Kla Somtrakul and Thipaporn Pohthawin \\ The Research Institute of North Eastern Arts and Culture, \\ Maha Sarakham University, Maha Sarakham, 44000, Thailand
}

\begin{abstract}
Problem statement: Local fishery was an inherited occupation for a long time. The objective of this research were to study: (1) the local fishery lifestyle of community in local fishery on upper area in Gulf of Thailand, (2) the appropriate participation process in natural resource management on upper part in Gulf of Thailand of people and organization and (3) the guidelines in natural resource management on the coastal area in upper part on Gulf of Thailand as relevant to local fishery lifestyle. Approach: The research area consisted of the shore of upper area in Gulf of Thailand including: Chachoengsao, Samutprakan, Samutsakon, Samutsongkram, Pechburi, Chonburi, Ra-yong, Chantaburi and Trad provinces. The samples as informants were 100 persons. The instruments using for data collection included the Survey, Interview Form, Observation Form, Record Form of Focus Group Discussion and Record Form of Participatory Workshop. The obtained data were classified into groups and investigated by using Triangulation Technique. Qualitative data were analyzed based on specified objectives. Results: The study of local fishery lifestyle found that there was location as in the present area owing to the fertility of area next to the sea. So, they could earn their living by fishery on coastal area. The local fishermen's lifestyle was simple. Their living places were wooden houses with high space under a Thai house. For relationship of relative groups, they still helped each other among community people. They had belief in guardian spirit of a ship or boat and Kromluang Choomponke dudomsak. They did traditional fishery. Most of their instruments were made by themselves and adapted based on appropriateness. The wisdoms were transferred within their family, (2) the participation process in appropriate natural resource management, found that based on problem situations of natural resource on coastal area in upper area on Gulf of Thailand, being destroyed. Consequently, community people and related work units, participated in natural resource management on shore of upper area in Gulf of Thailand and the ecological systems were organized for enhancing learning of natural resources. The public sector promoted by providing knowledge for people regarding to conservation as well as enhancing for growing the mangrove forest, inculcating aquatic animals, setting clubs for enhancing the youth's knowledge, the public sector work units collaborated in organizing useful activities for natural resource management and (3) the guidelines in natural resource management were implemented by requesting the support budget using in natural resource management on shore in upper part on Gulf of Thailand, trying to comprehend the reasons in passing the laws of enforcement, developing good understanding of people especially in students, inculcating the knowledge and understanding in natural resource in lesson of every class, encouraging for grouping the small group of entrepreneurs in developing bargaining power with capitalist, sharing wisdom in fishery among villagers. Conclusion/Recommendations: The public sector should participate in solving problems in management of conservative tourism, problem in communication as well as knowledge and understanding in natural resource of people in the area, enhancing network development among local fishery groups in each area in collaborating and sharing information with each other in order to have sustainability for local fishery in future.
\end{abstract}

Key words: Local fishery lifestyle, natural resources, coastal areas, upper area in gulf of Thailand, bargaining power, enhancing network, Qualitative data, community expansion, implementing activity, conservative tourism, aquatic animals, public sector

Corresponding Author: Sulak Sa-ngiamlak, The Research Institute of North Eastern Arts and Culture, Maha Sarakham University, Maha Sarakham, 44000, Thailand 


\section{J. Social Sci., 7 (4): 575-578, 2011}

\section{INTRODUCTION}

In recent time, there were problem situations of local fishery in each area of Thailand. As time went by, it would be more serious especially in destroy of natural resources on the shore as well as decrease of fish, the coral was demolished. In addition, the government officers were not able to control fisheries according to laws and regulations, the limitation on number of dragged purse net ship and pushed purse net to include appropriate level, couldn't achieve goal. Moreover, there was too much number in some kinds of instruments. Furthermore, there was ability in destroying aquatic animals and environment as well. Many kinds of the major sea fishery resource, were used inappropriately and unworthy. Besides, there was an impact from other fields of national development whether the industrial development, agriculture, tourism and community expansion. Although in reality or in practice, the public policy couldn't help resources on the shore to be revitalized very much since complex relationship and association of guidelines and related policy with fishery, resources on the shore and local fishery with a large number as well as responsibilities in great extent, were interesting to be studied in order to understand the problem clearer than the existing ones.

According to above reasons, the researcher viewed the importance of local fishery lifestyle and selection process of natural resource on shore in upper area on Gulf of Thailand. In this study, it was focused on studying lifestyle of local fishery in upper area on Gulf of Thailand by using fishermen's wisdom through transference from the past to recent time which would lead to utilize the sea resources with knowledge and comprehension in nature occurring in concrete form as custom and tradition as well as community regulations in sea, studying appropriate process in natural resource management on coastal area in Gulf of Thailand by collaboration of community people and organization and studying guidelines in natural resource management on shore in upper area Gulf of Thailand as congruence with local fishery lifestyle by allowing community have learning process both of policy, problem and related experience with natural resource management which couldn't be separated between community and local resource origin. They were created by community in expressing the attempt to access natural resource management on shore by the community. For this study, it would affect sustainable fishery resource usage, give an importance to creation in awareness of conservation and development by planning and determining direction in developing the natural resource management on coastal area by supporting community to participate in natural resource management on coastal area, affecting the way in local fishery occupation with more groups of those who earn living by fishery for solving community problems and cooperate with officers, making community be more self reliant by investigating, watching the violation and revitalizing fertility of the shore in order to prevent the dragged purse net, pushed purse net, in violating to catch aquatic animal in conservation area, helping local fishery lifestyle to be existed, obtaining valuable local wisdom which was useful for local fishery community as well as those who were interested in, using information as model and allowing community participate in sustainable natural resource management on coastal area and local fishery lifestyle in future.

\section{MATERIALS AND METHODS}

The studied area consisted the upper part of Thai Gulf including: Chachoensao, Samutprakan, Samutsakon, Samutsongkram, Pechburi, Chonburi, Rayong, Chantaburi and Trad Provinces. Qualitative research methodology was administered by collecting data from the samples selected as Purposive Sampling including: 25 experts, 50 practitioners and 25 general informants, total of 100 persons. The instrument using for collecting data included: the Survey, Interview Form, Observation Form, Focus Group Discussion and Record Form of Participatory Workshop, investigated by Triangulation according to the specified issues in research study and presented I descriptive analysis.

\section{RESULTS}

There were research findings as follows.

For the study of local fishery lifestyle of local fishery community in the area of Thai Gulf, found that the evacuation to locate in recent area because of fertility of area next to the sea. So, they could earn their living by fishery on the shore. The livelihood of local fishermen was simple. Most of their households situated on water edge as wooden houses with high under the house. The relationship in relative group was to help each other. They got together as a group in order to earn their living as local fisheries. They had their belief in female guardian spirit of a ship and Kromluang Choompon-kedudomsak used traditional fisheries. Most of their instruments were made by them. The instrument for catching aquatic animals was continuously adapted according to appropriateness. The wisdom in fisheries was transferred within family. 
For appropriate participation process of natural resource management on the shore in upper part of Thai Gulf of people and organization, found that the situation of natural resource problems on the coastal area in upper part on Gulf of Thailand, was destroyed. As a result, community people and related work units participated in natural resource management on the shore in upper area on Gulf of Thailand such as: (1) to get together as a group the conservative group into community for opposing the demolish of natural resource of the shore in upper part of Thai Gulf, (2) to get together as a group in managing ecological tourism for enhancing the study in natural resource conservation. The public sector encouraged people in the area by providing knowledge in conservation as well as encouragement in growing mangrove forest, cultivating aquatic animal. Klung Rachadapisek School established the clubs for promoting the mangrove forest growing. For aquatic animal cultivation, Klung Rachadapisek school, set up the clubs for enhancing knowledge provision for youth. In addition, public sectors had shared activities among them, for instance, Klung Rachadapisek School and station of resource development in mangrove forest 3 (Klung) organized activity for youngsters to grow the mangrove forest. Rampaipannee Rajabath University and Department of Environmental Quality Enhancement, Ministry of Natural Resource and Environment collaborated in enhancing the participation of people in area of Nongsano Subdistrict for conserving the natural resource.

For guidelines in natural resource management in upper part on Gulf of Thailand relevant to local fishery lifestyle, could be implemented by requesting for budget support using in natural resource management on the coastal area in upper part on Gulf of Thailand, try to understand in the reasons of the passed laws by providing knowledge and comprehension in natural resource conservation in lesson of every class, establishment of clubs in natural resource conservation in school, encouragement for grouping in small group of entrepreneurs for creating bargaining power with capitalists, development tin technique in fisheries, local fishery wisdom and product processing. The public sector should participate in problem solving in management of conservative tourism, problem of communication and knowledge and understanding of natural resource of people in community, encouragement in network development among groups of local fishermen in each area for supporting and sharing information together.

\section{DISCUSSION}

According to research findings, could be discussed as follows.

For local fishery lifestyle, process of participation in natural resource management on the shore, upper area of Thai Gulf and traditional livelihood had no problem since local fishermen living as sufficiency, depending on natural resource which there was enough for their need. It was supported by Poo-Inna et al. (2009). The results show that for community participation, found that every where allowed the community as follows: (1) collaborate in planning for implementation, (2) collaborate in practicing based on the specified plan of implementation, (3) collaborate in obtaining benefit and (4) collaborate in evaluation by the villagers and committee of local fish conservation regarding to worthwhile, the findings of performance of local fish conservation. Moreover, the committee of local fish conservation evaluated their own performance based on the assigned role and function in order to improve to be better..

For cultural network model, it was developed as the model after conducting research, implementing activity as connection and association in sharing network and evaluating the local fishermen's implementation success in order to set a group for coordinating shared benefit by systematically assigning the work task. It was supported by Saeng-Ngam et al. (2009). The results show that, People in the community have great opportunities to learn the pathway of development right from their own community cultures. They have learned the community problems and in unity, by means of brain storming to solve their own problems. This way of struggle, more or less, is the best way to escape from the domination of the people from the outside of the community

For participation in ecological management on the coastal area in upper area in Gulf of Thailand, it should emphasize on the leaders of activity performing by maintaining community style in fisheries. For occurred problems, the public sector and private sector had to participate in solving problems with people by perceiving the information, expressing opinion, making decision, practicing and obtaining benefit. It was supported statement that people's participation would lead to sustainable development, consisted of 5 steps: (1) participation in perception, be able to express one's ideas and suggestions, (2) participation in selection and presenting guidelines for decision making, (3) participation in decision making process, (4) participation in implementing for following up and investigation and (5) participation in obtaining benefit and being owner of work performance. 


\section{CONCLUSION}

The Ministry of Education should enhance the school under its jurisdiction in order to establish local curriculum for conserving the natural resources as well as applying fisherman's local wisdom providing information for children and youth in community to study and search for knowledge by allowing the elders in community with knowledge and competency in local fishery as well as conservation in the coastal natural resource conservation and local fishery lifestyle to be existed further.

The tourism of Thailand should participate in development of conservative tourism by allowing the community to participate in management every step as the owners of existing resources in community so that they would see the utilization from resources and conservation in their natural resources on the shore. The public sector should control, take care of, investigated the usage of natural resource on the shore. The community should be inculcated the approach so that they would be aware of as well as solve various problems occurring in their own community.

The headquarter of water police, Department of Fisheries, the station for development of mangrove forest and the shore, should coordinate collaboration among each other in order to increase efficiency in natural resource management. For the support, community should consider congruence principle with community need. For support and help, the benefit for community, should be considered and supported so that it wouldn't lead to conflict or internal changes in community.

There should be public relation and knowledge provision for people and youth should be thoroughly provided as well as dissemination of performance that would be useful for understanding of people and general people to be widespread both in the area level and educational institute in order to create the awareness and inculcate love of nature and environment. Specifically, the utilization and good point of natural resource conservation on the coastal area as well as the disadvantage and weak point in the shortage of natural resources on the coastal area, should be informed so that there would be collaboration. People should be encouraged to participate in most by coordinating with the educational work units to include in one part of local curriculum which would help the natural resource conservation on the coastal area to be successful quicker and lead to good benefit on natural resources of the country.

\section{REFERENCES}

Poo-Inna, S., S.K. Jantakajon and T. Pantachai, 2009. Appropriate model for zoning local fish conservation in front of buddhist temple on the bank of the chi river by sustainable community participation. J. Soc. Sci., 5: 411-415. DOI: 10.3844/jssp.2009.411.415

Saeng-Ngam, A., S. Chantachon and P. Ritthidet, 2009. the organization of cultural tourism by the community people in the region of Toong Kula Rong Hai. J. Soc. Sci., 5: 342-347. DOI: 10.3844/jssp.2009.342.347 